\title{
The Effect of Collaborative Dialogue on EFL Learner's Vocabulary Acquisition and Retention
}

\author{
Moussa Ahmadian \\ Dept. of English Language and Literature, Faculty of Humanities, Arak University \\ Arak 38156-8-8349, PO. Box: 879, Iran \\ E-mail: M.Ahmadian@araku.ac.ir \\ Majid Amerian \\ Dept. of English Language and Literature, Faculty of Humanities, Arak University \\ Arak 38156-8-8349, PO. Box:879, Iran \\ E-mail: M.Amerian@, araku.ac.ir \\ Azar Tajabadi (Corresponding Author) \\ Dept. of English Language and Literature, Faculty of Humanities, Arak University \\ Arak 38156-8-8349, Iran \\ E-mail: azar.taj08@gmail.com
}

Received: 30-01-2014

Accepted: 02-03-2014

Published: 01-07-2014

doi:10.7575/aiac.ijalel.v.3n.4p.38

URL: http://dx.doi.org/10.7575/aiac.ijalel.v.3n.4p.38

\begin{abstract}
Often associated with Vygotsky's socio-cultural theory, collaborative dialogue as a teaching technique has been frequently studied over the past few decades. There has been a great debate among experts and researchers regarding the effectiveness of this technique in facilitating the acquisition of second language skills in different educational contexts. Drawing upon an experimental design, the present study focused on the effect of collaborative dialogue on vocabulary acquisition and retention of EFL learners. Sixty-four Iranian lower intermediate EFL learners were homogenized by Oxford Placement Test, and were randomly divided into two collaborative and individual groups. A number of six tasks were developed and implemented at three stages of pre-task, during-task, and post-task. The learners in the collaborative group performed the tasks in groups of 3-4, while their counterparts in the individual group performed all the tasks individually. The learners' vocabulary knowledge was assessed using a researcher-made constructed-response vocabulary test in three occasions: pre-test, post-test, and follow-up-test. A set of independentsample t-tests was run to compare the groups' performance. The results revealed that the collaborative technique had significantly immediate and delayed effects on vocabulary acquisition and retention of the collaborative group. Possible reasons for this over-performance are discussed.
\end{abstract}

Keywords: vocabulary acquisition, vocabulary retention, collaborative dialogue, sociocultural theory, lower intermediate level

\section{Introduction}

In recent years, second language (L2) researchers have examined the role of interaction in language environment. In this regard, the impact of socially constructed nature of interaction on L2 learning has been studied from sociocultural perspectives (see Swain et al., 2002, for a review). For Vygotsky (1978), language mediates learning. On this basis, Swain (2000, p.97) elaborated on collaborative dialogue as a "dialogue in which speakers are engaged in problem solving and knowledge building". Though extended from the output hypothesis (Swain, 1985; 1995), it was in the sociocultural theory that collaborative dialogue was viewed as a tool of cognitive activity mediating language learning (Watanabe \& Swain, 2007). During such a dialogue, according to Swain and Watanabe (2013), speakers form and test hypotheses about language use, reflect on them, and refine their linguistic knowledge.

Embedded in the collaborative dialogue technique is the concept of Zone of Proximal Development (ZPD) proposed by Vygotsky (1978), which in his words is described as:

The distance between the actual development level as determined by independent problem solving and the level of potential problem solving as determined through problem solving under adult guidance or in collaboration with more capable peers (p. 86).

Fernandez et al. (2001) pointed out that Vygotsky refers only to "more able peers", implying the necessity of existence of an "intellectual asymmetry between participants in any joint activity" (p.40). However, other researchers have proposed that learning and development also occur in collaboration between learners at the similar level of understanding (Newman et al., 1989; Littleton \& Light, 1999; Cowie \& van der Aalsvort, 2000). Thus, when engaged in 
collaborative dialogue, the learners guide and support each other through discussion and interaction. This sharing of knowledge, and linguistic and cognitive resources have shown to lead to progress through the ZPD (Vygotsky, 1978; Oxford, 1997; Rowell, 2002; Jones, 2006).

The importance of collaborative dialogue as a mediating tool in learner-learner interaction has been investigated by previous research (Donato, 1994; Swain and Lapkin, 1998; Lantolf, 2000; Swain, 1995, 2000; Lantolf and Thorne, 2006). Among the extensive body of research in this field, acquisition of grammatical items has been the central focus (Swain and Lapkin, 1998; Storch, 1999; Kuiken and Vedder, 2002), while vocabulary learning has not received equal attention (Kim, 2008).

Investigating the acquisition of French reflexive verbs of Grade 8 French immersion students, Swain and Lapkin (1998) carried out a jigsaw activity consisting of sets of pictures based on which the students wrote a story working in pairs. Though the study followed a pretest-posttest design, the researchers also analyzed qualitatively the students' dialogues and detected language-related episodes (LREs). These episodes, which can have grammatical or lexical orientation, are parts of dialogue in which "the students talk about the language they are producing, question their language use, or correct themselves or others" (ibid, p.326). Overall, the researchers reported that the dialogue provides students with opportunities for language learning. However, Kim (2008) suggested that Swain and Lapkin's study would benefit from a more in-depth quantitative analysis.

In another study, Swain and Lapkin (2001) investigated the students' L2 learning employing two tasks, namely a dictogloss task and a jigsaw task. Following a pretest-posttest design, the researchers concluded that different tasks can result in different ranges of vocabulary use (higher in the jigsaw task). Once more, their study can be criticized in not associating the test results with the types of LREs. In the same line, Kim (2008) compared the impact of collaborative and individual tasks on L2 vocabulary acquisition by Korean learners. The participants were randomly assigned into two groups, namely Collaborative and Individual. In the practice sessions, the groups were introduced to the dictogloss task and practiced how to carry out similar tasks. Also, the individual group had additional sessions practicing thinkaloud protocols. In a subsequent session, the target task was completed by the participants. The data for the study were collected with pre-test, post-test, and follow-up-test. Also, the recordings from the groups were transcribed and analyzed for the occurrence of LREs. The quantitative analysis of the test results showed that the collaborative group acquired more vocabulary items (out of 15 target words). Furthermore, it outperformed the individual group in the follow-up-test, meaning that the retention of the words was better for the former. Nearly the same qualitative result was gained analyzing the LREs. Swain and Lapkin concluded that "collaborative tasks might be more beneficial for L2 vocabulary acquisition than the individual tasks" (ibid, p.124). That is, the questioning, repeating, and negotiating of language that occur in collaborative tasks can facilitate L2 acquisition.

In a recent paper by Khodamoradi et al. (2013), the effect of teacher's scaffolding versus peer collaborative dialogue on the acquisition of English tenses was studied. The scaffolding group and collaborative group of the study received different treatments. The students in the former group received teacher's assistance, while those in the latter group worked with their partners. A pre-posttest design was employed to assess the students learning. The comparison of test results showed no significant difference between the groups' performance.

Drawing upon Swain's (2005) notion of collaborative dialogue, Baradaran and Moezzy (2011) investigated the vocabulary acquisition of 60 intermediate EFL learners who were divided into an experimental group and a control group. A list of 30 words were taught to the participants in two different approaches. In the experimental group, the participants were engaged in three tasks designed to promote negotiation, while in the control group defining and memorizing the vocabularies were given. The participants of the experimental group attended an eight-session treatment aiming at introducing the concept of negotiation of meaning and practicing it in the tasks. The performance of each group in pre-posttests was compared by pated-sample t-tests. It was revealed that the participants in the control group did not show a significant improvement in vocabulary acquisition. Contrary to this result, the participants in the experimental group showed a significant difference between the two testing occasions meaning that they had acquired more vocabulary items. Although the mentioned study attempted to provide supporting evidence for employing collaborative dialogue in EFL contexts, it had a major drawback which might question the reliability of its results. As it was mentioned, the control group did not receive any treatment in the course of the study, while the experimental group had the opportunity to engage in introductory sessions as well as three highly motivating tasks. The problem of this approach is that the unequal treatment of the groups could negatively affect the control group while positively affect the experimental one. More support for the inadequacy of such a design can be found in Williams's (2001, cited in Kim, 2008, p.117) assertion that "without a control group (i.e., learners who complete an individual task), the relationship between the test results and the collaborative tasks is still in need of further investigation".

Despite these theoretical and practical propositions by the experts, a great debate still exists regarding the effectiveness of implementing collaborative dialogue in foreign language (FL) educational contexts, especially in those settings where the teachers hold an authoritative position and the learners are accustomed to a more passive role of the receiver of knowledge rather than an active contributor to it. Moreover, enquiries in this line of study reveals a gap in investigating the effects of employing collaborative dialogues on teaching vocabulary compared to other language skills and components. Also, the inadequacy and limitations of some research designs have blurred the validity and reliability of the obtained results. Therefore, the present study aims to investigate the effects of collaborative dialogue on vocabulary acquisition and retention of Iranian EFL learners. 


\section{Method}

\subsection{Research Questions and Hypotheses}

To investigate the above mentioned points, the following questions were raised:

1. Is there any significant difference between using collaborative dialogue and individual work in vocabulary acquisition of EFL learners?

2. Is there any significant difference between using collaborative dialogue and individual work in vocabulary retention of EFL learners?

Based on the aforementioned research questions, the following null hypotheses were formulated to be tested out:

1. There is no significant difference between using collaborative dialogue and individual work in vocabulary acquisition of EFL learners.

2. There is no significant difference between using collaborative dialogue and individual work in vocabulary retention of EFL learners.

\subsection{Vocabulary Selection}

A number of 90 words were the target of the study. The words were checked with englishprofile.org which assigned a level to each word according to the six-level scale of the Common European Framework of Reference (CEFR) for languages. This online program provides "reliable information at word and sentence levels, based on extensive analysis of word frequency and learner use" as claimed by Cambridge English Profile Corpus (CEPC), the British National Corpus (BNC), and the Cambridge Learner Corpus (CLC). The other criterion for selecting the words was Krashen's (1985) Comprehensible Input Hypothesis $(i+1)$, according to which the learning of language occurs only if the learners are provided with input (i) that is one level above their current level of understanding $(i+1)$. Thus, using English profile online engine, the level of each word was verified and only the words at the level of the participants (i.e., lower intermediate) and one level above it were selected for the present study.

\subsection{Participants}

A number of 64 Persian speaking homogenous EFL learners (male and female) aged 18-24 attending Sadr Institute of Higher Education in Isfahan, Iran, were selected to take part in this study. Their homogeneity in language proficiency was measured by the standardized Oxford Placement Test (OPT). The participants were evenly and randomly put into two groups: an experimental (here, collaborative) group and a control (here, individual) group.

\subsection{Instrumentation}

\subsubsection{Constructed-response Vocabulary Test}

In order to determine the participants' knowledge and understanding of the L2 vocabulary before and after the treatment, a constructed-response (CR) test was developed by the researchers. This test is one of the main forms of knowledge assessment (Simkin and Kuechler, 2005). The CR questions require the test takers to create answers in different types, including essay, short answers, and fill-in-the-blank (Kuechler and Simkin, 2010). Thus, these items measure production or recall, not recognition (Baker et al., 1994). The CR vocabulary test used in this study consisted of 90 items. Each item comprised a target word presented in a sentence. The test was piloted by 33 EFL learners with the same characteristics as the target participants including age, gender, and proficiency level. The mal-functioning items were detected by computing item facility and item distribution. Then, based on Henning (1987), the items with facility indexes below 0.33 and beyond 0.67 , and discrimination below 0.67 were deleted. Consequently, the final version of the test consisted 72 items (i.e. sentences). The Cronbach alpha coefficient was 0.72 and 0.79 before and after item deletion, respectively. According to Pallant (2007, p.98), the values above 0.7 show an acceptable internal consistency. The test was also validated against the standardized OPT two times: (i) with the whole OPT results, and (ii) only with the vocabulary part of the OPT test (i.e. 18 items) since this part was the focus of the study. The correlation between these sets of scores was found .81 and .78, respectively, which according to Cohen (1988, cited in Pallant, 2007, p.132) shows a strong relationship between the two tests. Thus, the existence of concurrent validity between the tests was confirmed.

\subsubsection{Tasks of Elicitation}

The selected words were implemented into six tasks which following Skehan (1996) were given to participants at the pre-task, during-task, and post-task stages. Also, activities implemented in each of these stages were chosen and modified from the options proposed by Skehan (1996) and Newton (2001). At the pre-task stage, first the tasks were introduced to the learners. The next step was dictionary search, in which the students were given a wordlist of 15 target words for each task along with their parts of speech. For each word, space was provided for writing a definition, a synonym, an antonym, or an L1 (i.e., Persian) equivalent. In the collaborative group, the dictionary search was done as a group work, while in the individual group, each individual student worked alone and filled in the wordlist within thirty minutes. For the during-task stage, among Newton's (2001) three cooperative options (i.e., activities): glossary, interactive glossary, and negotiation, only glossary was chosen. The word glossary here refers to the wordlist completed by the students at the pre-task stage. As a post-test activity, vocabulary log was chosen. The students were asked to look back over the words that they had encountered in the pre-task and during-task stages to specify five words based on their preference and fill in the logs. 


\subsection{Procedure}

The treatment consisted of 9 two-hour sessions (totally 18 hours) held in a time span of 35 days. In the first session, the participants took the OPT and the pre-test. Based on the OPT results, they were randomly assigned into collaborative and individual groups. One week later, the treatment started for six sessions in two weeks. In the $8^{\text {th }}$ session, the posttest was given to the participants. Two weeks later, in the $9^{\text {th }}$ session, the follow-up test was administered.

Different approaches were employed for teaching the vocabulary to the two groups. In the collaborative group, the participants were put into small groups of three-four and were guided to do the tasks collaboratively. For the individual group, the same tasks were used, with the difference that the task completion in each session was done individually by each participant (i.e. no pair or group word) and with the teacher's minimum direct collaboration.

\section{Results}

The nature of the constructed-response vocabulary tests called for subjective scoring. In order to minimize the effects of any bias on the scores, three raters who were proficient and acquainted enough with the subject of the test (i.e., vocabulary) were asked to score the tests according to a scoring rubric. The scores given by the raters in the pre-post and follow-up tests were computed via the $20^{\text {th }}$ version of SPSS and through descriptive statistics, correlation coefficient, and t-tests. Table 1 shows the results of descriptive statistics of the raters' scores given to the participants in the two groups.

Table 1. Descriptive Statistics of the Rater's Scores in Pre-Post \& Follow-up Tests

\begin{tabular}{lllllll}
\hline & \multicolumn{2}{c}{ Rater 1 } & \multicolumn{3}{c}{ Rater 2 } & Rater 3 \\
\cline { 2 - 7 } & $M$ & $S D$ & $M$ & $S D$ & $M$ & $S D$ \\
\hline Pre-test & 8.67 & 2.30 & 8.31 & 2.08 & 8.17 & 2.06 \\
\hline Posttest & 48.09 & 10.57 & 47.95 & 10.59 & 48.00 & 10.41 \\
\hline Follow-up test & 41.22 & 13.37 & 41.05 & 13.32 & 41.13 & 13.53 \\
\hline
\end{tabular}

According to this table, the raters' mean scores in the pre-test are very close, that is, $M=8.67$ for rater $1, M=8.31$ for rater 2, and $M=8.17$ for rater 3. The same pattern is followed in post-test results, in which $M=48.09$ for rater $1, M=47.95$ for rater 2, and $M=48.00$ for rater 3. This consistency is maintained in the follow-up-test results, so that $M=41.22$ for rater $1, M=41.5$ for rater 2, and $M=41.13$ for rater 3 . Although these mean scores indicate a close agreement between the raters in scoring the tests, to further investigate the relationship (i.e., agreement) between the scores provided by the raters in the pre-post and follow-up-tests, Pearson product-moment correlation coefficient was computed (see Table 2). As shown in this table, there was a strong agreement between the raters, since all the values are above the criteria $(\mathrm{r}$ $=.50$ to 1.0 ). Thus, the scores had high inter-rater agreement.

Table 2. Pearson Coefficient Correlation of the Rater's Scores in Pre-Post \& Follow-up Tests

\begin{tabular}{lccc}
\hline Pre-test Scores & Rater 1 & Rater 2 & Rater 3 \\
\hline Rater 1 & - & $.92^{* *}$ & $.93^{* *}$ \\
\hline Rater 2 & $.92^{* *}$ & - & $.91^{* *}$ \\
\hline Rater 3 & $.93^{* *}$ & $.91^{* *}$ & - \\
\hline Posttest Scores & Rater 1 & Rater 2 & Rater 3 \\
\hline Rater 1 & - & $.99^{* *}$ & $.99^{* *}$ \\
\hline Rater 2 & $.99^{* *}$ & - & $.99^{* *}$ \\
\hline Rater 3 & $.99^{* *}$ & $.99^{* *}$ & - \\
& & & \\
\hline Follow-up Scores & Rater 1 & Rater 2 & Rater 3 \\
\hline Rater 1 & - & $.99^{* *}$ & $.99^{* *}$ \\
\hline Rater 2 & $.99^{* *}$ & - & $.99^{* *}$ \\
\hline Rater 3 & $.99^{* *}$ & $.99^{* *}$ & - \\
\hline$* *$ Correlation is significant at the 0.01 level (2-tailed) &
\end{tabular}

Because of this high inter-rater agreement, the average score of each set was considered as the main score for each subject and was used for comparisons. Table 3 presents the mean scores and standard deviations of the scores for the two groups in three tests.

Table3. Descriptive statistics for the Collaborative and Individual Groups

\begin{tabular}{lllll}
\hline & \multicolumn{2}{l}{ Collaborative Group } & \multicolumn{2}{l}{ Individual Group } \\
\cline { 2 - 5 } & $M$ & $S D$ & $M$ & $S D$ \\
\hline Pre-test & 8.60 & 1.74 & 8.12 & 2.23 \\
\hline Posttest & 58.04 & 4.40 & 38.69 & 3.32 \\
\hline Follow up test & 54.08 & 5.07 & 28.66 & 4.90 \\
\hline
\end{tabular}


According to Table 3, the mean of pretest scores of the two groups revealed no significant difference on the vocabulary knowledge of the participants. Thus, the participants were at the same level of vocabulary knowledge before instruction. This result was also statistically confirmed by running independent-sample t-test (see Table 4) which indicates no significant difference between the two groups ( $\mathrm{t}(62)=-.772$ and $\mathrm{p}=.44$ (two-tailed)).

Table 4. Independent sample T-test of the Collaborative and Individual Groups in the Pretest

\begin{tabular}{llll}
\hline Groups & $d f$ & $T$ & Sig. \\
\cline { 1 - 1 } Collaborative Group & 62 & -.772 & 0.44 \\
\cline { 1 - 1 } Individual Group & & & \\
Level of significance .05 (2-tailed) & &
\end{tabular}

\subsection{Hypothesis1.}

Immediately following the instruction, the post-test was administered. Based on the results tabulated in Table 3, there was a large difference between the scores for collaborative groups $(\mathrm{M}=58.04, \mathrm{SD}=4.40)$ and individual $(\mathrm{M}=38.69$, $\mathrm{SD}=3.32$ ) after vocabulary treatment. Also, another independent-sample t-test was run to compare the post-test scores. As shown in Table 5, the $p$ value is less than $.05(.00<.05)$, this means that the two groups had a meaningful difference in their vocabulary acquisition after receiving the treatment; thus it shows the out-performance of the collaborative group over the individual one.

Table 5. Independent sample T-test of the Collaborative and Individual Groups in the Post-test

\begin{tabular}{llll}
\hline Groups & $d f$ & $T$ & $P$ \\
\hline Collaborative Group & 60 & -16.58 & .00 \\
\hline Individual Group & & & \\
Level of significance .05 (2-tailed) & &
\end{tabular}

Based on the aforementioned results, the first null hypothesis of this study was rejected, which means that there is a significant difference between using collaborative dialogue and individual work in vocabulary acquisition of EFL learners.

\subsection{Hypothesis 2.}

Two weeks after the treatment, a follow-up-test was administered to the participants of the groups. The test scores of collaborative and individual groups were compared. The results indicated a large difference between the scores of collaborative groups $(\mathrm{M}=54.08, \mathrm{SD}=5.07)$ and individual $(\mathrm{M}=28.66, \mathrm{SD}=4.90)$ (see Table 3$)$. The results of a third independent-sample $\mathrm{t}$-test showed a statistically significant difference between the groups' scores ( $\mathrm{t}(56=-19.397, p=$ .00 (two-tailed)). Thus, the collaborative group out-performed the individual group in the follow-up-test, showing that the collaborative dialogue technique was more effective in vocabulary retention of the participants. This result, thus, rejects the second null hypothesis. In other words, there is a significant difference between using collaborative dialogue and individual work in vocabulary retention of EFL learners.

Table 6. Independent sample T-test of the Collaborative and Individual Groups in Follow-up Test

\begin{tabular}{llll}
\hline Groups & $d f$ & $T$ & Sig. \\
\hline Collaborative Group & 56 & -19.397 & .00 \\
\cline { 1 - 1 } Individual Group & & & \\
\hline
\end{tabular}

Level of significance .05 (2-tailed)

\section{Discussion}

The current study focused on how the participants engaged in collaborative dialogue may differ from those who performed individually on the tasks in terms of their L2 vocabulary acquisition and retention. The comparison of posttest results indicated a significant difference between the two groups. The collaborative group's scores on the post-test drastically increased; this can be regarded as convincing evidence that collaborative interactions between the peers at the same level of proficiency can mediate their language learning. This finding is in line with Storch's (1999) findings that learners perform better in tasks when they work together rather than working alone. One of the reasons for this can be the facilitative effect of negotiation of meaning on acquisition, as stated by Long (1996). He maintains that such an effect results from the fact that negotiation connects input, learners' capabilities, and output.

Collaborative dialogue, as one of the forms of interaction, among peers can function as instructional conversations between experts and learners (Swain, 1995). This kind of dialogue provides the learners with "opportunities to coconstruct a complex linguistic structure by focusing their attention and providing opportunities to revise their own language use" (Swain \& Watanabe, 2013: 3218). As it was observed in the present study, the learners in the collaborative group grasped such opportunities by asking questions, explaining their choices, and elaborating upon their 
knowledge. In this way, the peers tutored and mediated the learning process of their peers (Barnard, 2002, Lantolf, 2000); this resulted in a significant difference between the performance of the collaborative learners and the individual ones.

It was previously mentioned that peers can collaborate by sharing knowledge in working on a language task (Le, 2003). The requirement for this collaboration is language. Language in collaborative negotiation goes beyond its immediate function as just a means for communication. It enables people to help others to learn or "co-construct knowledge together" (Mercer, 1995, p.4). Lexical items are essential components in a language. In this regard, Long $(1981,1983)$ proposes that learners can understand words beyond their present level of competence by negotiating their meanings with other learners. This collaborative act, can promote acquisition since learners eventually can incorporate the negotiated items in their production. For Pica (1994), this negotiated interaction can positively affect learning lexical items in a language, because it is more concerned with lexical items than grammatical ones (see also Pica et al, 1993; Mackey et al, 2004; Dobao, 2012). The statistical analysis of the post-test results, confirms this line of enquiry that collaborative dialogue between the peers in a learning context may be beneficial in the acquisition of lexical items.

It should be noted that students in the individual group acquired a considerable number of vocabulary items. This result might be justifiable regarding the fact that the mere act of presenting the participants with the target vocabulary and the tasks can have an impact on their learning. It is, however, inevitable to realize the importance of student's reliance on their own knowledge in the process of task completion and learning. But, as shown in the present study, when the learners' knowledge is questioned and negotiated in the process of collaboration (Swain et al., 2002), the result is a higher gain of target vocabulary items; this finding is also in line with the findings of Storch (1999), Leeser (2004), Watanabe \& Swain (2007), and Kim (2008) who came to similar conclusions.

The same pattern was found in the follow-up test. Although both groups had a decrease in their mean of performance after a two-week interval, the participants of the collaborative group out-performed their counterparts in the individual group. The higher retention of the vocabulary items by the collaborative participants can be the result of their active engagement in the process of task completion. That is, when working together to solve linguistic problems, the repetition and negotiation of the linguistic items (here words) might result in their easier retrieval.

To summarize, the findings of the current study support the positive effect of employing the collaborative techniques for peers at the same level of proficiency on the vocabulary acquisition and retention. Further research is also needed to investigate possible impacts of gender and different proficiency levels as important variables in the effectiveness of the collaborative dialogue technique and the students' perceptions.

\section{Conclusions and Implications}

The findings of this study show that a more social technique such as collaborative dialogue in the context of language learning can benefit the learners' acquisition and retention of L2 vocabulary. The collaborative learning environment enables the learners to construct their ZPD collaboratively in the presence of peers at the same level of proficiency and conceptual understanding. This active construction of the learning environment by the learners also affects positively the retention of the acquired vocabulary items. These results can have pedagogical implications for implementing collaborative dialogue techniques in language classes, suggesting that learners can solve linguistic problems more effectively when they receive support from their peers rather than when they work alone. This can aid EFL teachers who are required to manage language classes with a large number of learners. In such classes, the use of pair or group work can be a beneficial resource for the learners in promoting L2 (vocabulary) acquisition, and for teachers in managing the classes.

In this study, the selected lexical items were at or above the present level of the learners. Though this posed a challenge to the learners, it was observed that when the responsibility of learning vocabulary is given to the learners, they can make the given input comprehensible through interacting with peers (interactionally modified input). This finding can benefit the teachers in that when faced with time constraints they can share the task of teaching with the learners. In addition, if teachers worry about the correct and complete learning of the lexical items, they can provide follow-up activities or review sessions to check the learners' acquisition and retention of the intended items.

\section{References}

Baker, E., O'Neil, H., \& Linn, R. (1994). Policy and validity prospects for performance-based assessment. Journal for the Education of the Gifted, 17(4), 331-353.

Baradaran, A., \& Moezzy, M. (2011). A study of the role of collaborative negotiation in the acquisition of lexical meaning. Australian Journal of Basic and Applied Sciences, 5(21), 2252-2259.

Barnard, R. (2002). Peer tutoring in the primary classroom: A sociocultural interpretation of classroom interaction. New Zealand Journal of Educational Studies, 37(1), 57-72.

Cowie, H., \& van der Aalsvort, G. (Eds.). (2000).Social Interaction in Learning and Instruction. Oxford: Pergamon.

Doboa, F. A. (2012). Collaborative Dialogue in Learner-Learner and Learner-Native Speaker Interaction. Applied Linguistics, 33(3), 229-256.

Donato, R. (1994). Collective scaffolding in second language learning. In J. P. Lantolf \& G. Appel (Eds.), Vygotskian approaches to second language research (pp. 33-56). Ablex, Norwood: NJ. 
Fernández, M., Wegerif, R., Mercer, N. \& Rojas-Drummond, S. (2001). Re-conceptualizing 'scaffolding' and the ZPD in the context of symmetrical collaborative learning. Journal of Classroom Interaction, 36(2), 40-54.

Henning, G. (1987). A guide to language testing. Cambridge, MA: Newbury House.

Jones, L.C. (2006). Effect of collaboration and multimedia annotations on vocabulary learning and listening comprehension. CALICO Journal, 24(1), 33-58.

Krashen, S.D. (1985). The Input Hypothesis. Harlow: Longman.

Khodamoradi, A., Irvani, H., Jafarigohar, M., \& Amerian, M. (2013). Teacher's scaffolding vs. peers' collaborative dialogue: implementing an innovation in the sociocultural context of Iranian universities. Middle-East Journal of Scientific Research, 14(9), 1212-1220.

Kim, Y. (2008). The contribution of collaborative and individual tasks to the acquisition of L2 vocabulary. The Modern Language Journal, 92(1), 114-30.

Kuechler, W. L. \& Simkin, M. (2010). Why Is Performance on Multiple-Choice Tests and Constructed-Response Tests Not More Closely Related? Theory and Empirical Test. Decision Sciences Journal of Innovative Education, 8(1), 55-73.

Kuiken, F. \& Vedder, I. (2002). The effect of interaction in acquiring the grammar of a second language. International Journal of Educational Research, 37(3), 343-358.

Lantolf, J. P. (2000). Introducing sociocultural theory. In J. P. Lantolf (Ed.), Sociocultural Theory and Second Language Learning (pp. 1-26). Oxford, England: Oxford University Press.

Lantolf, J.P. \& Thorne, S.L. (2006). Sociocultural theory and the genesis of second language development. Oxford: Oxford University Press.

Le, Houng. (2003). What does a more knowledgeable peer mean? A socio-cultural analysis of group interaction in a Vietnamese classroom. Paper presented at the NZARE/AARE Joint Conference, Auckland.

Leeser, J. M. (2004). Learner proficiency and focus on form during collaborative dialogue. Language Teaching Research, 8(1), 55-81.

Littleton, K. \& Light, P. (Eds). (1999). Learning with computers: analyzing productive interaction. Routledge Publication, London.

Long, M. H. (1981). Input, interaction, and second language acquisition. In H. Winitz (Ed.), Native language and foreign language acquisition: Annals of the New York Academy of Sciences (pp. 259-278). New York: New York Academy of Sciences.

Long, M. H. (1983). Native speaker/non-native speaker conversation and the negotiation of comprehensible input. Applied Linguistics, 4(2), 126-141.

Long, M. H. (1996). The role of the linguistic environment in second language acquisition. In W. C.Ritchie \& T. K. Bhatia (Eds.), Handbook of second language acquisition (pp. 413-468). San Diego, CA: Academic Press.

Mackey, A., Polio, C. \& McDonough, K. (2004). The relationship between experience, education and teachers' use of incidental focus-on-form techniques. Language Teaching Research, 8(3), 301-27.

Mercer, N. (1995). The Guided Construction of Knowledge: talk amongst teachers and learners. Clevedon: Multilingual Matters.

Newman, D., Griffin, P., \& Cole, M. (1989). The Construction Zone. Cambridge: Cambridge University Press.

Newton, J. (2001). Options for vocabulary learning through communicative tasks. ELT Journal, 55(1), 30-37.

Oxford, R. (1997). Cooperative learning, collaborative learning, and interaction: Three communicative strands in the language classroom. The Modern Language Journal, 81(4), 443-456.

Pallant, J. (2007). SPSS Survival Manual: A Step by Step Guide to Data Analysis Using SPSS for Windows. (3 ${ }^{\text {rd }}$ ed.). New York: Open University press.

Pica, T. (1994). Research on negotiation: What does it reveal about second language learning conditions, processes, and outcomes?. Language Learning, 44(3), 493-527.

Pica, T., Kanagy, R., \& Falodun, J. (1993). Choosing and using communication tasks for second language instruction. In G. Crookes \& S. Gass (Eds.), Tasks and language learning: Integrating theory and practice (pp. 9-34). Clevedon, UK: Multilingual Matters.

Simkin, M. G. \& Kuechler, W. L. (2005). Multiple-choice tests and student understanding: what is the connection?. Decision Sciences Journal of Innovative Education, 3(1), 73-98.

Skehan, P. (1996). A framework for the implementation of task-based instruction. Applied Linguistics, 17(1), 38-62.

Storch, N. (1999). Are two heads better than one? Pair work and grammatical accuracy. System, 27(3), 363-374.

Rowell, P. M. (2002). Peer interactions in shared technological activity: A study of participation. International Journal of Technology and Design Education, 12(1), 1-22. 
Swain, M. (1985). Communicative competence: Some roles of comprehensible input and comprehensible output in its development. In Gass, S. and Madden, C. (Eds.), Input in second language acquisition (pp. 235-256). New York: Newbury House.

Swain, M. (1995). Three functions of output in second language learning. In G. Cook and B. Seidlhofer (Eds.), Principles and Practice in Applied Linguistics (pp.125-144). Oxford: Oxford University Press.

Swain, M. (2000). The output hypothesis and beyond: Mediating acquisition through collaborative dialogue. In J. P. Lantolf (Ed.), Sociocultural Theory and Second Language Learning (pp. 97-114). Oxford, England: Oxford University Press.

Swain, M. (2005). The output hypothesis: Theory and research. In E. Hinkel (Ed.), Handbook of research in second language teaching and learning (pp. 471-484). Mahwah, NJ: Lawrence Erlbaum.

Swain, M., \& Lapkin, S. (1998). Interaction and second language learning: Two adolescent French immersion students working together. The Modern Language Journal, 82(3), 320-337.

Swain, M., and Lapkin, S. (2001). Focus on form through collaborative dialogue: Exploring task effects. In Bygate, M. et al. (Eds.), Researching pedagogic tasks (pp. 99-118). Pearson Education.

Swain, M., and Lapkin, S. (2002). Talking it through: Two French immersion learners' response to reformulation. International Journal of Educational Research, 37(3-4), 285-304.

Swain, M., \& Watanabe, Y. (2013). Language: Collaborative Dialogue as a Source of Second Language Learning. In C. A. Chapelle (Ed.), The Encyclopedia of Applied Linguistics (pp. 3218-3225). Hoboken, NJ: Wiley-Blackwell.

Swain, M., Brooks, L., \& Tocalli-Beller, A. (2002). Peer-peer dialogue as a means of second language learning, Annual Review of Applied Linguistics, 22(1), 171-185.

Watanabe, Y., \& Swain, M. (2007). Effects of proficiency differences and patterns of pair interaction on second language learning: collaborative dialogue between adult ESL learners. Language Teaching Research, 11(2), 121 -142.

Vygotsky, L.S. (1978). Mind in Society: The Development of Higher Psychological Processes. Cambridge, MA: Harvard University Press. 